\title{
A GESTÃO DE RESÍDUOS SÓLIDOS E SEUS REFLEXOS NA QUALIDADE AMBIENTAL URBANA DE MARINGÁ-PR
}

Kelly Cristina RIGOLDI ${ }^{1}$

Valéria LIMA²

Otávio Cristiano MONTANHER3

\begin{abstract}
Resumo
O aumento do consumo de produtos descartáveis gera o crescimento gradativo de resíduos sólidos. Estes, quando não destinados de maneira correta, provocam impactos ambientais e sociais, por isto, a adequada gestão dos resíduos sólidos é importante para a qualidade ambiental urbana. A partir desta premissa, o presente artigo pretende demonstrar a importância da coleta seletiva para a manutenção da qualidade ambiental, partindo da análise da gestão dos resíduos sólidos da cidade de Maringá, por meio dos dados da coleta seletiva e convencional do ano de 2015 até o primeiro semestre de 2018. Com as análises dos dados, concluiu-se que a gestão da coleta seletiva é ineficaz, apesar de ter apresentado diminuição no contingente coletado na coleta convencional e aumento de apenas $1 \%$ na seletiva no primeiro semestre de 2018. Portanto, são necessárias ações para sensibilizar a comunidade e melhorar a gestão e o controle na coleta dos recicláveis, com local de triagem para mais eficiência no direcionamento dos materiais para as cooperativas.
\end{abstract}

Palavras-chave: Coleta seletiva; Reciclagem; Meio ambiente urbano; Impactos ambientais; Gestão de resíduos sólidos.

\section{THE MANAGEMENT OF SOLID WASTE AND ITS REFLECTIONS ON THE URBAN ENVIRONMENTAL QUALITY OF MARINGÁ-PR}

\begin{abstract}
The increase in consumption of disposable products generates the gradual growth of solid waste. These, when not properly disposed, cause environmental and social impacts, that is why the proper management of solid waste is important for urban environmental quality. Based on this premise, the present article intends to demonstrate the importance of selective collection for the maintenance of environmental quality, starting from the analysis of solid waste management in the city of Maringá, using data from selective and conventional collection from 2015 to the first semester of 2018. Based on data analysis, it was

\footnotetext{
1 Mestranda pelo Programa de Pós-Graduação em Geografia da Universidade Estadual de Maringá - UEM. Integrante do Grupo de Estudos e Pesquisas Ambiente, Sociedade e Geotecnologias - GEPAG. E-mail: kellyrigoldi@gmail.com

${ }^{2}$ Professora dos cursos de Graduação e Pós-Graduação em Geografia da Universidade Estadual de Maringá - UEM. Doutora em Geografia pelo Programa de Pós-Graduação da FCT/UNESP. E-mail: vlima@uem.br

3 Graduado em Geografia pela Universidade Estadual de Maringá - UEM. Integrante do GEMA Grupo de Estudos Multidisciplinares do Ambiente. E-mail: otaviocmontanher@yahoo.com.br
} 
concluded that the management of selective collection is ineffective, despite having shown decrease in the contingent collected in conventional collection and increase of only $1 \%$ in selective collection in the first half of 2018. Therefore, actions are needed to sensitize the community and improve management and control in the collection of recyclables with a sorting location for greater efficiency in directing materials to cooperatives.

Keywords: Selective collection; Recycling; urban environment; Environmental impacts; Solid waste management.

\section{GESTIÓN DE RESIDUOS SÓLIDOS Y SUS REFLEJOS EN LA CALIDAD AMBIENTAL URBANA DE MARINGÁ-PR}

\section{Resumen}

El aumento del consumo de productos descartables genera el crecimiento gradual de residuos sólidos. Cuando no destinados de manera correcta, tales desechos provocan impactos ambientales y sociales, por esto la adecuada gestión de restos sólidos es importante para la calidad ambiental urbana. A partir de esa premisa, este artículo posee la finalidad de presentar la importancia de la recogida selectiva para el mantenimiento de la calidad ambiental a partir del análisis de la gestión de los residuos sólidos de la ciudad de Maringá, com los datos de la colecta selectiva y de la convencional desde 2015 hasta el primer semestre de 2018. Con el análisis de los datos, se concluyó que el manejo de la recolección selectiva es ineficaz, a pesar de haber presentado disminución en el contingente recolectado en la recolección convencional y aumento de solo 1\% en la recolección selectiva en el primer semestre de 2018. Por lo tanto, se necesitan acciones como actividades educativas para sensibilizar a la comunidad, mejorar la gestión y control en la recogida de los reciclables, con local de selección para el direccionamiento más eficiente de los materiales para las cooperativas.

Palabras clave: Recogida selectiva; Reciclaje; Medio ambiente urbano; Impactos ambientales; Gestión de residuos sólidos.

\section{INTRODUÇÃO}

A acentuação do consumo de produtos descartáveis é um dos responsáveis pelo aumento da geração de resíduos sólidos. Estes provocam diversos impactos ambientais e sociais, tais como a contaminação dos solos e das águas, assim como a proliferação de vetores de doenças.

A intensificação das relações de consumo foi impulsionada, em um primeiro momento, pelas revoluções industriais, entretanto, no Brasil, esta revolução se deu de maneira mais intensa a partir da segunda metade do século XX, com o aumento populacional nas cidades. De acordo com Santos (2006), o 
meio "Técnico-Científico-Informacional" impulsionou o processo de produção do espaço e, também, dos objetos que o ocupam, neste sentido, com o aumento de produtos descartáveis, intensificou-se a geração de resíduos sólidos e os problemas ambientais resultantes da disposição e gestão inadequada desses, comprometendo a qualidade ambiental e colocando em risco a saúde da população.

A qualidade ambiental, conforme Marques (2005), compreende o quadro positivo ou negativo de determinado espaço geográfico com relação aos aspectos físicos e sociais, para os quais são necessários indicadores de avaliação. Os resíduos sólidos são um indicador importante na avaliação ou análise da qualidade ambiental urbana, considerando seus impactos para o meio ambiente e para a população. Para tal, a coleta seletiva atua com a finalidade de minimizar os impactos causados pela alta produção de resíduos sólidos. A cidade de Maringá, conforme a Prefeitura do Município de Maringá - PMM( [s. d.]), possui coleta seletiva ativa desde 2001, conta com o Plano Municipal de Gestão Integrada dos Resíduos Sólidos (PMGIRS), elaborado em 2017, que possui metas de diminuição da quantidade de resíduos coletados e aumento da coleta seletiva. É considerada uma cidade de porte médio e está localizada, segundo o Instituto Brasileiro de Geografia e Estatística (IBGE), na mesorregião norte central Paranaense, com área territorial de 487.052 km², com população urbana estimada em 417.0104 (Figura 1).

4 População urbana estimada calculada para o ano de 2018, de acordo com dados do Instituto Brasileiro de Geografia e Estatística - IBGE 
Figura 1: Localização do Município de Maringá

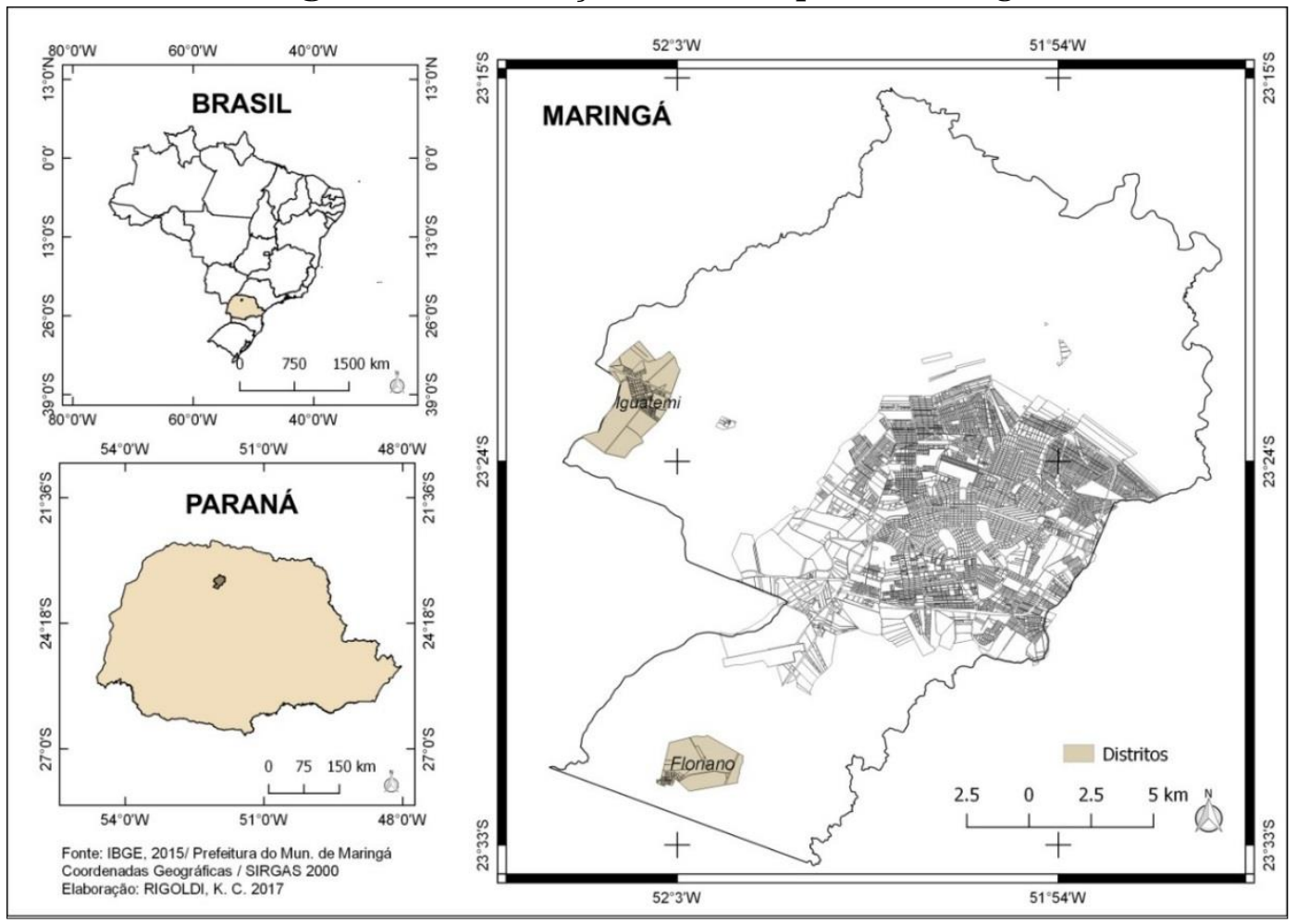

Fonte: Rigoldi e Lima (2018).

Com relação à coleta de resíduos sólidos, Maringá possui duas modalidades de coleta: a convencional e a seletiva. Nesta última, os materiais coletados são encaminhados para seis cooperativas que separam e compactam os materiais para comercialização e reciclagem.

Maringá, em 2017, produziu, em média, $285^{5}$ toneladas de resíduos sólidos diários, uma média de 720 gramas/habitante por dia de resíduos, dos quais apenas 3,2\% deste total foram destinados à coleta seletiva, entretanto, aproximadamente, 33\% de todo o resíduo coletado é reciclável (PREFEITURA DO MUNICÍPIO DE MARINGÁ, 2018).

Considerando o crescimento populacional identificado em Maringá nos últimos anos, a importância da coleta seletiva e o Plano Nacional de Resíduos Sólidos, este artigo tem como objetivo discutir a gestão dos resíduos sólidos da cidade de Maringá, com base nos dados da Secretaria Municipal de Serviços Públicos (SEMUSP, 2018) e do Plano Municipal de Gestão Integrada dos Resíduos Sólidos (PREFEITURA DO MUNICÍPIO DE MARINGÁ, 2017).

5 Dados fornecidos pela Secretária Municipal de Serviços Públicos - SEMUSP, a partir do protocolo $\mathrm{n}^{\circ} 2786 / 2018$ (SEMUSP, 2018, online). 


\section{A IMPORTÂNCIA DA GESTÃo DOS RESÍDUOS SÓlIDOS PARA A QUALIDADE AMBIENTAL}

Para analisar a qualidade ambiental, é necessário considerar os indicadores socioambientais que possam indicar o grau de comprometimento de determinada área que, conforme Marques (2005), compreende a mensuração da condição ambiental positiva ou negativa da localidade estudada. De acordo com Mendonça (2004), a dissonância existente entre os processos antrópicos e naturais se manifesta por meio de impactos ambientais, os quais apresentaram muita expressão a partir do desenvolvimento industrial nos últimos 200 anos, principalmente, no meio ambiente urbano. Entretanto, os problemas ambientais urbanos se acentuaram a partir da segunda metade do século $\mathrm{XX}$, diante do aumento demográfico nas cidades atrelado à política consumista instaurada na mesma época. Conforme Ramos, Santos e Oliveira (2019), o modo de vida capitalista estimulado pelo consumismo põe em risco não apenas a qualidade ambiental, mas também a qualidade de vida dos indivíduos.

Santos (2006) afirma que o meio técnico-científico-informacional impulsiona os processos de transformação da natureza e de construção do espaço geográfico, de modo que a natureza é incapaz de reparar as degradações no mesmo tempo em que são geradas. Também Mendonça (2004) destaca que esse processo de dessincronia entre a sociedade e a natureza atua sob duas perspectivas, em que, em uma delas, a cidade é cenário do desenvolvimento que provoca impactos na natureza e, na outra, as ocupações na periferia da cidade são realizadas de maneira precária, em áreas irregulares e sem assistência e, deste modo, são afetadas pelos processos da natureza.

Conforme Marques (2005), o meio ambiente urbano é representado por aglomerações humanas, que deve possuir infraestrutura adequada para a população bem como reduzir ou evitar os impactos ambientais gerados pelas atividades ali presentes.

Os problemas ambientais urbanos, geralmente, estão vinculados ao inadequado planejamento das cidades e ao processo de produção desigual dos espaços dentro da ótica do sistema capitalista, impulsionado pelo mercado 
imobiliário, e atingem, majoritariamente, as classes sociais menos favorecidas economicamente.

Sendo assim, existe uma estreita relação entra a produção do espaço e o avanço dos problemas ambientais, estes considerados na qualidade ambiental, a qual requer uma análise integrada de diversos fatores, sejam eles físicos, sejam biológicos e/ou antrópicos. Conforme Ramos, Santos e Oliveira (2020), é pela relação direta entre os problemas ambientais, os recursos naturais e a saúde humana que o gerenciamento de resíduos vem ganhando destaque no mundo.

Neste sentido, Hogan (1995) apontou que os indicadores que devem ser levados em consideração para a análise da qualidade ambiental são: 0 saneamento básico, a disposição final dos resíduos sólidos, a poluição sonora e visual bem como a do ar, os espaços verdes, e a relação - solo-água.

Com relação aos resíduos, a gestão inadequada destes é um dos principais problemas nas cidades, em especial, em relação à disposição final, podendo gerar inúmeros impactos, como a poluição tanto visual quanto do ar, dos solos e da água, além disso, se tornam uma questão sanitária, influenciando a saúde pública.

\section{OS RESÍDUOS SÓLIDOS URBANOS}

Conforme Mendonça (2004), a aglomeração urbana desencadeou uma série de impactos, estes em decorrência da debilidade das técnicas de saneamento, do descaso com produção e do descarte de resíduos sólidos domésticos. O consumo, segundo Rodrigues (1998), é associado à ideia de bemestar, contribuindo, assim, para a construção e o desenvolvimento de uma "sociedade do descartável".

Muitas vezes, o termo resíduo sólido é associado ao de lixo, porém existem diferenças em suas definições. A partir de uma perspectiva econômica, conforme Cancian (1981), resíduo refere-se a todo material descartado ou desperdiçado pela sociedade, tanto por falta de conscientização como por ausência de uma gestão adequada de coleta e de mercado para compra e reciclagem desses materiais. 
A Associação Brasileira de Normas e Técnicas (ABNT), em sua normativa NBR 100004 (ABNT, 2004, p. 1), diz que

Os resíduos nos estados sólido e semi-sólido, que resultam de atividades de origem industrial, doméstica, hospitalar, comercial, agrícola, de serviços e de varrição. Ficam incluídos nesta definição os lodos provenientes de sistemas de tratamento de água, aqueles gerados em equipamentos e instalações de controle de poluição, bem como determinados líquidos cujas particularidades tornem inviável o seu lançamento na rede pública de esgotos ou corpos de água, ou exijam para isso soluções técnica e economicamente inviáveis em face à melhor tecnologia disponível.

Segundo o artigo $13^{\circ}$ da lei $n^{\circ} 12.305$, de 2010 (BRASIL, 2010, online), que rege o Plano Nacional de Resíduos Sólidos (PNRS), resíduos sólidos compreendem tudo o que é remanescente da limpeza urbana, sendo esses provenientes de áreas públicas, comerciais, industriais, residenciais bem como de atividades de serviços como transporte, construção civil e, ainda, os oriundos das atividades agrossilvopastoris e de mineração. Neste, também é abordada a periculosidade dos resíduos sólidos, que representam risco à qualidade ambiental bem como à saúde pública, por apresentarem características inflamáveis, reativas, carcinogênicas, corrosivas, toxicidade, patogenicidade, mutagenicidade e teratogenicidade.

Diante disto, o artigo $\mathrm{n}^{0} 9$ da lei 12.305/10, do PNRS, define critérios em ordem de prioridades na gestão dos resíduos sólidos: "não geração, redução, reutilização, reciclagem, tratamento dos resíduos sólidos e disposição final ambientalmente adequada dos rejeitos” (BRASIL, 2010, online).

Os resíduos são subdivididos em duas categorias principais, os que são considerados passíveis de recuperação, os quais denominamos Materiais Recicláveis ou Secos que, conforme Monteiro et al. (2001), compreendem papéis, metais, vidros e plásticos, sendo estes materiais que possam ser destinados aos processos de reciclagem e possuem valor comercial. A outra categoria são os identificados como rejeitos, ou seja, materiais que não são passíveis de reutilização.

Moraes (2011) evidencia que os impactos da alta produção dos resíduos sólidos estão vinculados à disposição final inadequada, podendo gerar a 
poluição do ar pela liberação de gazes, como o dióxido de carbono (CO2), pelas contaminações dos solos, de águas superficiais e subterrâneas por meio do líquido produzido na decomposição de alguns materiais, como o chorume ${ }^{6}$. Pessoa et al. (2019) alertam, também, para a poluição visual, assim como para o desequilíbrio da flora e fauna em decorrência do mesmo fator. Desse modo, é perceptível a importância da disposição correta desses materiais, ou seja, em aterros sanitários.

A coleta seletiva apresenta um papel fundamental no processo de separação, coleta e destinação desses materiais, tendo em vista que ela pode diminuir a quantidade de resíduos descartados inadequadamente e o volume destinados aos aterros sanitários.

\section{A COLETA SELETIVA COMO FERRAMENTA NA GESTÃO DOS RESÍDUOS SÓLIDOS URBANOS}

Para o processo de reciclagem, é necessário que ocorra a coleta dos materiais secos, que pode ser realizada de três formas, conforme Monteiro et al. (2001): a coleta seletiva porta a porta, que consiste em uma sistematização da área urbana da cidade, de modo que, uma vez por semana, ocorre a coleta dos materiais recicláveis nas casas; pontos de entrega voluntárias (PEV), que são constituídos por contêineres, os quais devem estar devidamente sinalizados, e a população dispõe, voluntariamente, os materiais recicláveis; e por cooperativas de catadores, que se deslocam de porta a porta a fim de recolher os resíduos recicláveis. Entretanto, qualquer uma das formas de coleta depende de um processo de educação ambiental que conscientize e sensibilize a população, além de uma gestão adequada.

De acordo com o Plano Nacional de Resíduos Sólidos - PNRS (2012), em síntese, as formas citadas acima entram na classe da coleta seletiva formal, ou seja, aquela subsidiada ou realizada pelas prefeituras. Além desta, o plano categoriza, também, a coleta seletiva informal, que compreende a coleta dos resíduos recicláveis por catadores autônomos, não sendo contabilizados pelas prefeituras.

6 Conforme IPT (2018), chorume: líquido turvo e malcheiroso, proveniente da decomposição do lixo, podendo estar misturado com água da chuva, denominado, também, percolado. 
Após o processo de coleta, é necessária a triagem dos materiais coletados, a fim de eliminar os que não são passíveis de reutilização e ou contaminados. Posteriormente, o material é destinado à comercialização para empresas, recicladores ou sucateiros, cuja reciclagem será, efetivamente, realizada.

Peixoto et al. (2005) indicam que contribuir com o processo de reciclagem é uma prática que leva à manutenção e preservação do meio ambiente e, consequentemente, à construção de sustentabilidade futura.

Os benefícios ambientais, como a diminuição de materiais destinados aos aterros, colaboram para o aumento de vida útil dessas áreas bem como a preservação de recursos naturais por meio da reutilização. Cantóia (2012) destaca a importância desses programas na geração de empregos e renda para diversas famílias que são excluídas do mercado formal de trabalho.

Desse modo, os resíduos sólidos não destinados à coleta seletiva são direcionados a outro tipo de coleta, a convencional ou regular, segundo Monteiro et al. (2001), esta modalidade é responsável pelo recolhimento de todos os resíduos não passíveis de reutilização. Entretanto, quando a coleta seletiva não atua de maneira efetiva, muitos materiais recicláveis são considerados rejeitos.

Monteiro et al. (2001) alertam, ainda, que cabem às prefeituras a organização e atuação da coleta regular nos municípios, sendo ela municipal ou terceirizada, neste sentido, é de responsabilidades das mesmas a apresentação de locais adequados para a disposição final dos rejeitos. Neste sentido, a Prefeitura do Município de Maringá (2017) reconhece a responsabilidade de o fazer de maneira adequada.

\section{PROCEDIMENTOS METODOLÓGICOS}

A análise apresentada neste artigo teve como base os dados mensais das coletas seletiva e convencional de resíduos sólidos de Maringá, dos anos 2015, 2016, 2017 e do primeiro semestre de 2018, os quais foram disponibilizados pela Secretaria Municipal de Serviços Públicos (SEMUSP). O período analisado tem relação com os registros e a disponibilidade dos dados das coletas, 
considerando controle da quantidade de resíduos coletados pela coleta convencional a partir de 2012, e da seletiva de 2015, realizado pela SEMUSP.

Para a realização da relação entre contingente populacional e resíduos sólidos gerados na cidade, foi necessário calcular a estimativa populacional urbana dos anos analisados, para isto, foram utilizados os dados dos censos de 1991, 2000 e 2010 do IBGE, como base para o cálculo de distribuição da população urbana e rural do município de Maringá, tendo em vista que esses não estão disponíveis para os anos analisados. Desse modo, os dados estimativos populacionais de 2015, 2016, 2017 e 2018 foram obtidos a partir da análise de média aritmética, com a proporção entre população urbana e rural, as quais apresentaram média simples de $98 \%$ e $2 \%$, respectivamente. Com base no teste de normalidade Jarque-Bera que, segundo Gujarati e Porter (2011), analisa a distribuição dos dados baseada no cálculo da assimetria e da curtose, verificando se elas apresentam distribuição normal, ou seja, o teste avalia a hipótese nula de que os resíduos são normalmente distribuídos, o desvio padrão e a variância das estimativas foram baixos, e a distribuição foi considerada normal, com $p<0,05$, aumentando o grau de confiabilidade dos dados estimados.

Analisou-se a existência de tendência nas séries temporais, considerando a coleta convencional e a coleta seletiva como duas séries independentes. A análise de regressão linear foi aplicada, em que foi adotado o nível de significância de $5 \%$. Neste teste, a hipótese nula $\left(\mathrm{H}_{0}\right)$ é que o coeficiente angular da reta ajustada para a série de dados não difere de zero (em termos de notação convencional: $\left.\beta_{1}=0\right)$. Por outro lado, a hipótese alternativa $\left(\mathrm{H}_{1}\right)$ é o resultado da rejeição da hipótese nula, ou seja, o coeficiente angular difere de zero $\left(\beta_{1} \neq 0\right)$.

No caso de o coeficiente angular ser diferente de zero, pode-se afirmar a existência de uma tendência temporal (linear, de aumento ou diminuição). Com base no nível de significância adotado, de 5\%, para que o coeficiente angular seja considerado significativamente diferente de zero, o valor-p deve ser inferior a $5 \%$ (ou 0,05, em probabilidade). Tais conceitos estão relacionados à inferência estatística e podem ser consultados em Bussab e Morettin (2013).

A análise de regressão, no entanto, necessita a avaliação de alguns pressupostos para que possa ser utilizada para avaliação de tendências 
temporais. O primeiro pressuposto que foi avaliado relaciona-se à existência de sazonalidade na série. Como será demonstrado na seção de resultados, observou-se um efeito sazonal para a série de coleta convencional, efeito não observado na série de coleta seletiva. Portanto, para minimização da variância relacionada à sazonalidade, a regressão foi aplicada sobre as anomalias da série de coleta convencional (Equação 1), transformação não necessária para a série de coleta seletiva.

Em que:

$$
A=\frac{X_{m}-\mu_{m}}{\sigma_{m}}
$$

- A = anomalia correspondente ao valor de X (adimensional);

- $\mathrm{X}_{\mathrm{m}}=$ coleta convencional para determinado mês m (ton./mês);

- $\mu_{\mathrm{m}}=$ coleta convencional média dos meses m (ton./mês);

- $\sigma_{\mathrm{m}}=$ desvio padrão da coleta convencional dos meses m (ton./mês).

Outro pressuposto avaliado foi o de normalidade dos resíduos da regressão, em que o método de Kolmogorov-Smirnov (K-S) foi aplicado. O K-S é um teste analítico que avalia o grau de aderência entre a distribuição empírica (observada a partir dos dados) e determinada distribuição teórica. O teste foi primeiramente desenvolvido por Andrei N. Kolmogorov, na década de 1930, e, posteriormente, modificado por Nikolai V. Smirnov, na década de 1940 (DAS; IMON, 2016).

Além dessas etapas, foram analisadas a cobertura e atuação dos serviços de coleta a partir dos dados fornecidos pela SEMUSP (2018) e, a partir de trabalhos de campo, foram identificadas as áreas de disposição irregular de resíduos sólidos na cidade. Também foram realizadas visitas técnicas ao aterro sanitário e ao antigo vazadouro da cidade. Os mapeamentos realizados para auxiliar as análises foram elaborados no software Q Gis, versão 2.18.23 (QGIS, [s. d.], online).

\section{GESTÃO DOS RESÍDUOS SÓLIDOS DA CIDADE DE MARINGÁ}

Maringá possui dois tipos de coletas, a convencional, que funciona desde 1947, e abrange toda a malha urbana, e a seletiva, que foi idealizada em 1994, e iniciou suas atividades em 2001. 
Segundo a Prefeitura do Município de Maringá (2017), desde o início, o programa de coleta seletiva passou por diversas mudanças. Entretanto, apenas em 2017 foi estruturado de maneira que toda a área urbana fosse contemplada dentro do plano de gestão de resíduos sólidos na cidade.

Sobre a destinação dos recicláveis coletados, a Prefeitura do Município de Maringá (2017), por meio do PMGIRS, reconhece a distribuição para as seis cooperativas cadastradas sob contrato de prestação de serviços com a prefeitura. A Lei $n^{0}$ 12.69o/12 (BRASIL, 2012, online), em seu artigo $n^{0}$ 2, considera:

Cooperativa de Trabalho a sociedade constituída por trabalhadores para o exercício de suas atividades laborativas ou profissionais com proveito comum, autonomia e autogestão para obterem melhor qualificação, renda, situação socioeconômica e condições gerais de trabalho.

A distribuição dos resíduos sólidos recicláveis, de acordo com a SEMUSP (2018)7, é realizada conforme o tipo de resíduo que cada cooperativa recebe: Cooperpalmeira, Coopermaringá, Coopernorte, Cooperambiental (estas recebem todo tipo de resíduo reciclável), Coopercanção (recebe eletrônicos), Coopervidros (recebe vidros). A prefeitura possui contrato com uma sétima cooperativa, que trabalha de maneira diferenciada, denominada Coopercicla, pois atua com equipamentos e recursos próprios, não recebendo materiais derivados da coleta seletiva realizada pela prefeitura, e não possui nenhum acompanhamento da quantidade arrecadada.

De 2011 a 2016, o serviço de coleta seletiva da cidade ficou sob responsabilidade de uma empresa terceirizada e não atendia a toda a cidade, ou seja, apenas 50\% era atendida por esse (Figura 2). Neste momento, apenas a frota de caminhões era terceirizada, a coleta era realizada pelos cooperados das seis cooperativas. De setembro de 2015 a setembro de 2016, todo o serviço passou a ser terceirizado e, depois deste período, foi municipalizado.

7 Informação coletada diretamente com a secretaria, sob o protocolo $n^{0}$ 2786/2018. 
Figura 2: Cobertura da coleta seletiva em Maringá (2016 e 2017)

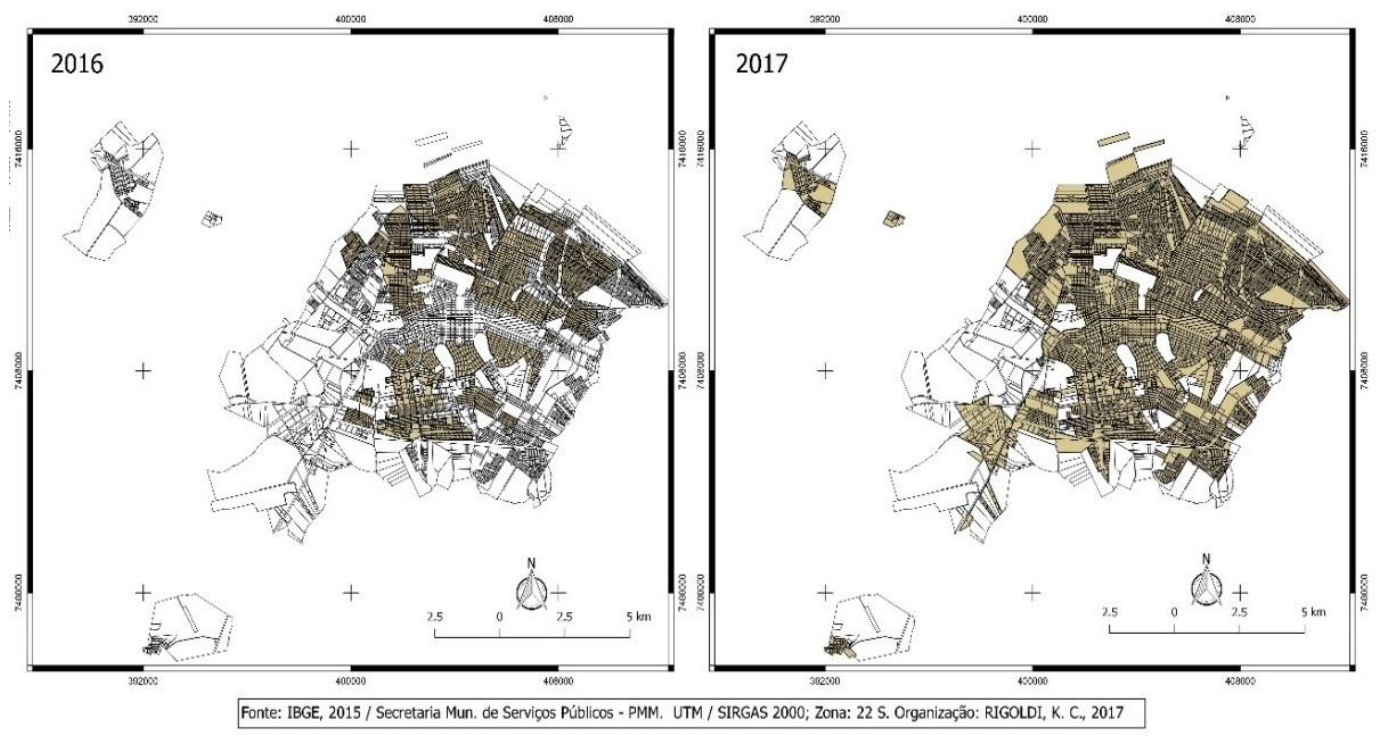

Elaborado por RIGOLDI, K. C..

Conforme a Prefeitura do Município de Maringá (2017), o programa de coleta seletiva da cidade funciona na modalidade porta a porta, na qual a população separa, previamente, o material, e os caminhões da prefeitura passam recolhendo. O próprio órgão reconhece a necessidade de um trabalho de educação ambiental e orientação da população em relação à separação dos recicláveis para a coleta seletiva.

A cidade foi sistematizada em setores, os quais cada um recebe a coleta seletiva uma vez na semana, e a zona central é atendida todos os dias, de segunda a sexta-feira, no período noturno, de acordo com o PMGIRS da Prefeitura do Município de Maringá (2017).

Em abril de 2018, o programa de coleta seletiva passou por novas mudanças, com a contratação de motoristas e coletores, e o aumento de caminhões coletores para atender a toda a cidade, totalizando 15 caminhões. Outra modificação foi a distribuição de sacolas biodegradáveis de 100 litros, com informações educativas. Tais alterações tinham o objetivo de triplicar os materiais coletados pelo programa.

Os novos caminhões destinados ao programa, bem como os motoristas e coletores, foram terceirizados, e os materiais coletados continuaram destinados para as seis cooperativas cadastradas na prefeitura. 


\section{ANÁLISE DA COLETA SELETIVA NA CIDADE DE MARINGÁ}

Utilizou-se o termo resíduos sólidos para os materiais coletados também pela coleta convencional, tendo em vista a constatação de que parte dos resíduos secos não eram coletados separadamente.

Como mencionado anteriormente, a coleta seletiva atua desde 2001, mas o controle da quantidade do material coletado começou em 2015. Entre os anos de 2015 e 2017, ocorreu aumento na coleta de resíduos recicláveis pela coleta seletiva, mas não atingiu o estipulado pela prefeitura, que seria de $1 / 3$ da coleta convencional.

Em 2017, houve a municipalização da coleta convencional e, de acordo com a SEMUSP (2018), devido à falta de equipamentos, a coleta seletiva não estava atuando da maneira planejada, e não existia controle das áreas que estavam sendo atendidas pelo serviço, dessa maneira, neste período, não foi possível precisar a abrangência efetiva do programa.

A partir desses dados, foi constatado que, em média, por dia, foram coletados 722 gramas de resíduos sólidos, por habitante, pela coleta convencional, e apenas 20 gramas de materiais recicláveis pela coleta seletiva. Esta última coletou apenas 2,8\% de recicláveis por dia e não atingiu a meta estipulada pela prefeitura municipal (Tabela 1).

Tabela 1: Resíduos coletados entre 2015 a 2018

\begin{tabular}{|c|c|c|c|c|}
\hline \multicolumn{5}{|c|}{ MATERIAL COLETADO PELA COLETA SELETIVA - 2015 a 2018} \\
\hline & \multicolumn{3}{|c|}{ ANOS } & \multirow[b]{2}{*}{$\begin{array}{c}1^{\circ} \text { semestre } \\
2018\end{array}$} \\
\hline VARIÁVEIS & 2015 & 2016 & 2017 & \\
\hline POPULAÇÃO & 389.483 & $\mathbf{3 9 4 . 9 9 6}$ & 398.553 & 402.111 \\
\hline REJEITO KG/DIA & 300.016 & 287.648 & 284.175 & 295.199 \\
\hline KG REJEITO HAB/DIA & $\mathbf{0 , 7 5 5}$ & $\mathbf{0 , 7 1 4}$ & 0,699 & $\mathbf{0 , 7 3 4}$ \\
\hline RECICLÁVEL KG/DIA & 6.939 & 8.555 & 9.291 & 11.467 \\
\hline KG RECICLÁVEL HAB./DIA & $\mathbf{0 , 0 1 7}$ & $\mathbf{0 , 0 2 1}$ & $\mathbf{0 , 0 2 3}$ & $\mathbf{0 , 0 2 8}$ \\
\hline
\end{tabular}

Fonte: SEMUSP, 2018. Elaborado por RIGOLDI, K. C..

A coleta convencional possui um pico nos meses de dezembro e janeiro, provavelmente, está relacionado ao período de férias e festas, aumentando a produção de resíduos, enquanto nos outros meses, a média é parecida (Gráfico 1). Esse aumento da coleta nesses meses justificou a adoção dos valores de 
anomalias para o teste de tendência da coleta convencional, justamente para remoção deste efeito sazonal. Por outro lado, a série de coleta seletiva não apresenta variações sazonais, ao menos para o período avaliado (Gráfico 1).

Gráfico 1: Médias e desvio padrão mensais da coleta de resíduos sólidos de Maringá
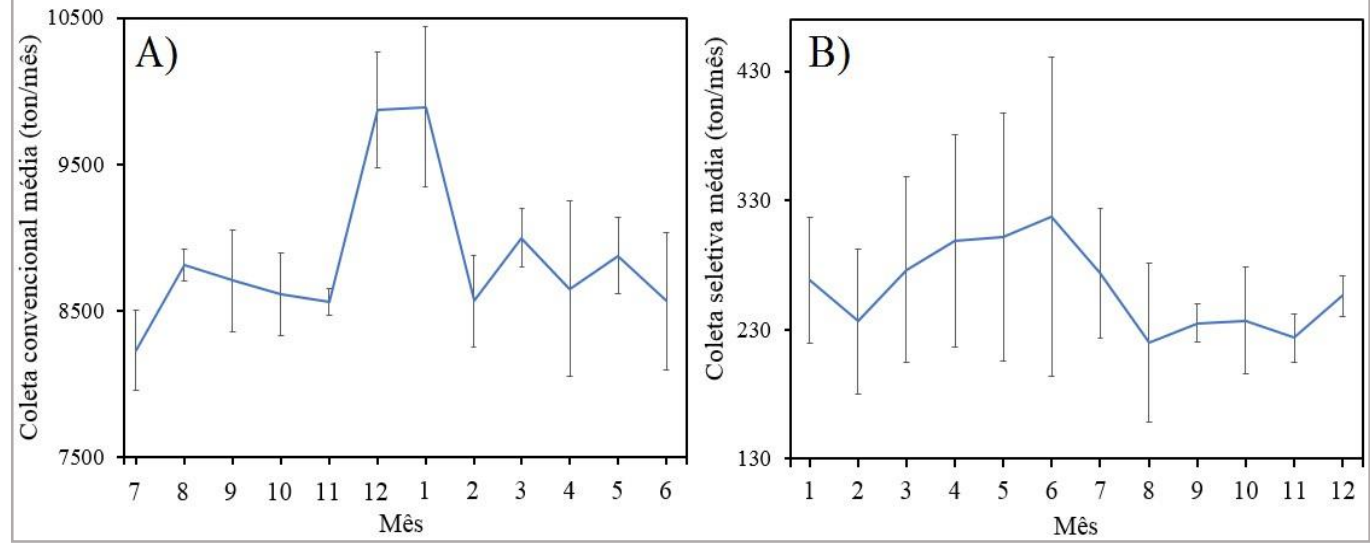

Fonte: SEMUSP 2015 a 2018. Elaborado por MONTANHER, O. C..

No Gráfico 2, percebe-se diminuição nos valores da coleta convencional, e no Gráfico 3, aumento da seletiva. Ambas as tendências foram significativas para $\alpha=5 \%$, e pôde-se assumir o pressuposto de normalidade dos resíduos para este mesmo limiar.

Gráfico 2: Tendência da coleta convencional de resíduos sólidos de Maringá

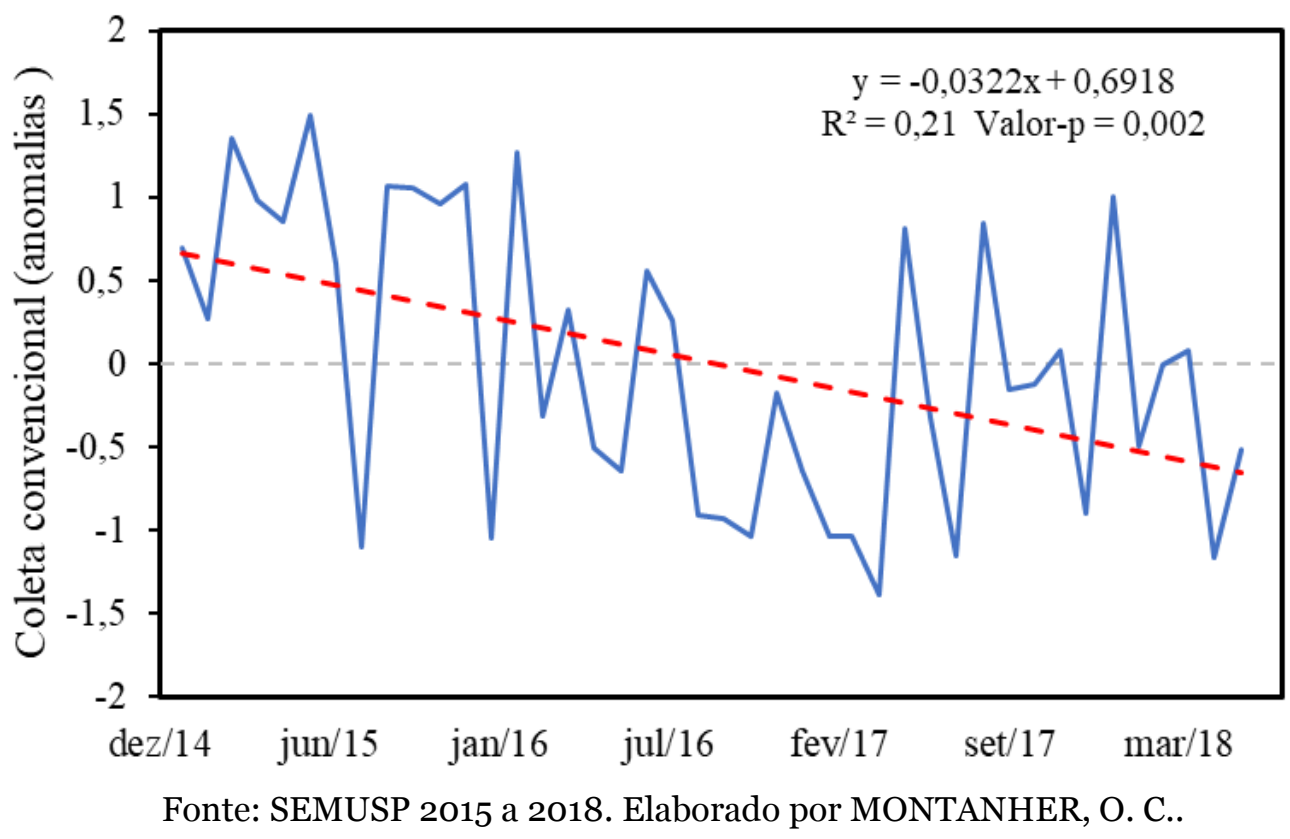


Gráfico 3: Tendência da coleta seletiva de resíduos sólidos de Maringá

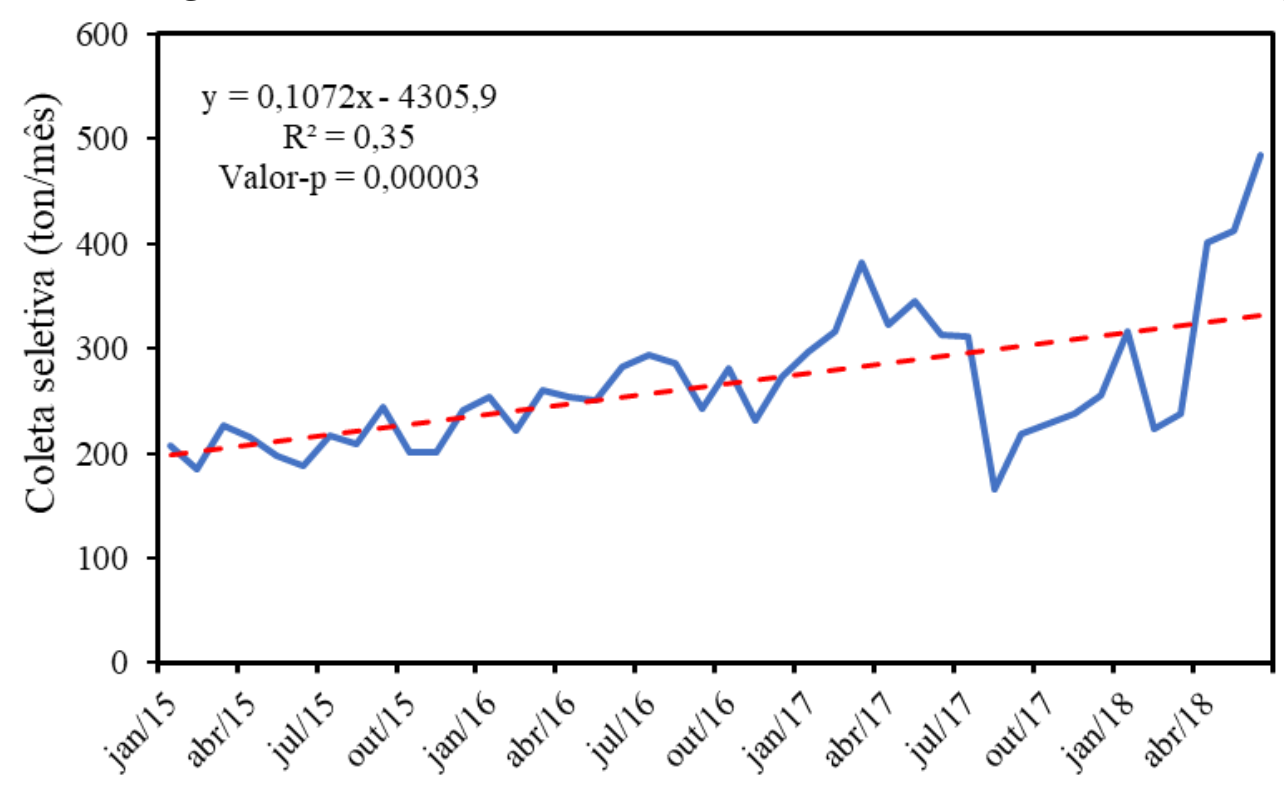

Fonte: SEMUSP 2015 a 2018. Elaborado por MONTANHER, O. C..

Os picos identificados da coleta seletiva, presentes no Gráfico 2, referemse às mudanças que ocorreram no programa pela prefeitura, como em março de 2017, quando foi expandida a coleta para toda a malha urbana, e em abril de 2018, quando aumentou a frota de caminhões e houve a distribuição dos sacos biodegradáveis com a divulgação do novo calendário da coleta. As quedas identificadas no gráfico se referem aos momentos de falha na atuação do serviço identificados na análise dos dados indicados pela SEMUSP (2018) e Prefeitura do Município de Maringá (2017).

Mesmo considerando a diminuição e o aumento da coleta convencional e da seletiva, respectivamente, as variações nos anos de 2015 a 2017 foram baixas e imperceptíveis no volume recebido, diariamente, no aterro sanitário. Em abril de 2018, a coleta seletiva teve aumento no contingente coletado, entretanto, este ainda não foi significativo. Neste mesmo período, a quantidade coletada pela coleta convencional também apresentou aumento, e apenas nos meses de maio e junho do ano de 2018, houve redução, as quais, a partir da análise dos dados, não apresentam relações proporcionais.

Com base nas análises, a coleta seletiva ainda não atingiu a meta proposta pela prefeitura de triplicar o contingente coletado inicialmente, 
considerando que houve apenas o aumento de $1 \%$ no primeiro semestre de 2018 na coleta seletiva.

Considerando a inexpressividade do volume de recicláveis coletado pela coleta seletiva e o aumento populacional de Maringá de 2017 para 2018, estimado pelo IBGE (2018), que foi de mais de 10 mil habitantes para este período, pode acarretar o aumento gradual do volume de resíduos.

Além desses fatores, com relação à coleta seletiva, foram identificadas outras questões vinculadas à gestão dos resíduos sólidos de Maringá, como as áreas de disposição dos resíduos sólidos do município.

\section{ÁREAS DE DISPOSIÇÃO FINAL DOS RESÍdUOS/REJEITOS DE MARINGÁ}

Maringá, desde sua fundação, em 1947, de acordo com a Prefeitura do Município de Maringá (2017), contou com dois vazadouros, o primeiro funcionou de 1957 até 1974, e suas atividades foram encerradas pela aproximação da área urbana do mesmo. Nesta área, atualmente, se localiza um centro educacional de ensino superior da rede privada. A partir de 1974, outra área foi destinada como vazadouro, a qual ficou ativa até o ano de 2006. Após diversas notificações e a autuação do Instituto Ambiental do Paraná - IAP, esse aterro começou a funcionar, como aterro controlado, de 2006 até 2010 (Figura 3). Esta área foi definitivamente embargada em 2010, sob interferência do IAP. A partir de licitações, neste mesmo ano, foi contratado o serviço de aterro sanitário da empresa Pedreira Ingá (PREFEITURA DO MUNICÍPIO DE MARINGÁ, 2017, online). 
Figura 3: Áreas de disposição final de resíduos sólidos já utilizados em Maringá

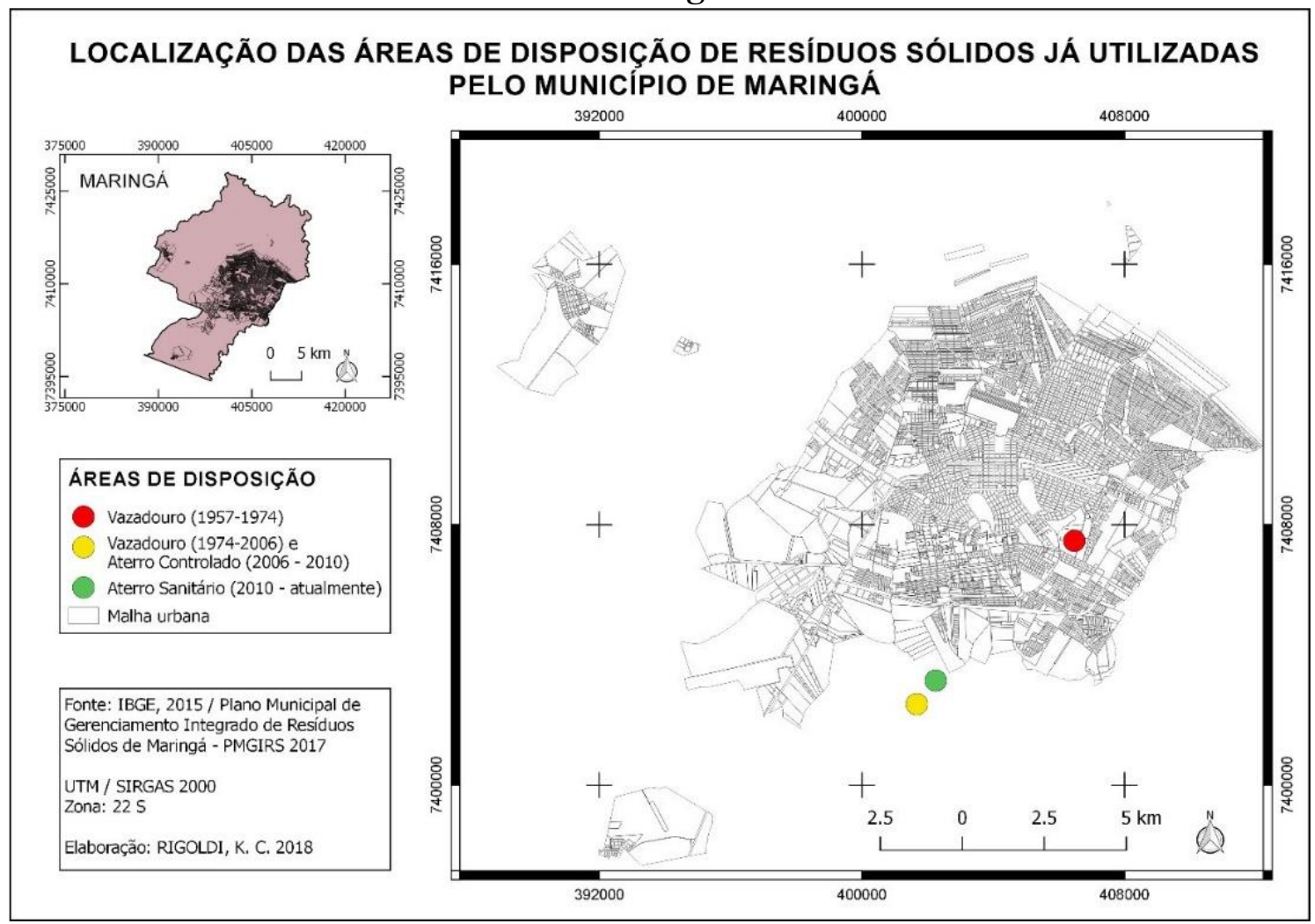

Fonte: Rigoldi e Lima (2018).

A área que foi utilizada até 2010 como aterro controlado conta com bacias de contenção do chorume, mas que se encontram em péssimas condições de manutenção, como foi possível identificar em visitas realizadas ao local em 2017, 2018 e 2019. Esta área apresenta vegetação arbórea com predominância da espécie Leucaena leucocephala, que, segundo Costa e Durgan (2010), é uma espécie exótica, a qual configura risco ao desenvolvimento da vegetação nativa, assim como ruderal, esta definição, segundo os autores, corresponde a espécies não nativas que se proliferam em áreas degradadas ou perturbadas.

O aterro sanitário que atende à cidade de Maringá se localiza dentro de uma pedreira ativa e possui áreas não contínuas de disposição de resíduos. A empresa, após o cessar da extração de minérios em determinados locais, prepara a área para receber os rejeitos, sendo que o local é aterrado e nivelado para receber a manta de geomembrana de alta densidade como agente impermeabilizante. Em seguida, são realizadas a cobertura de solo e a alocação de drenos horizontais e verticais que são responsáveis pela liberação de gás bem 
como pela captação do chorume. Após este processo, a área está apta a receber os rejeitos (Figura 4).

Figura 4: Áreas do aterro sanitário e antigo vazadouro

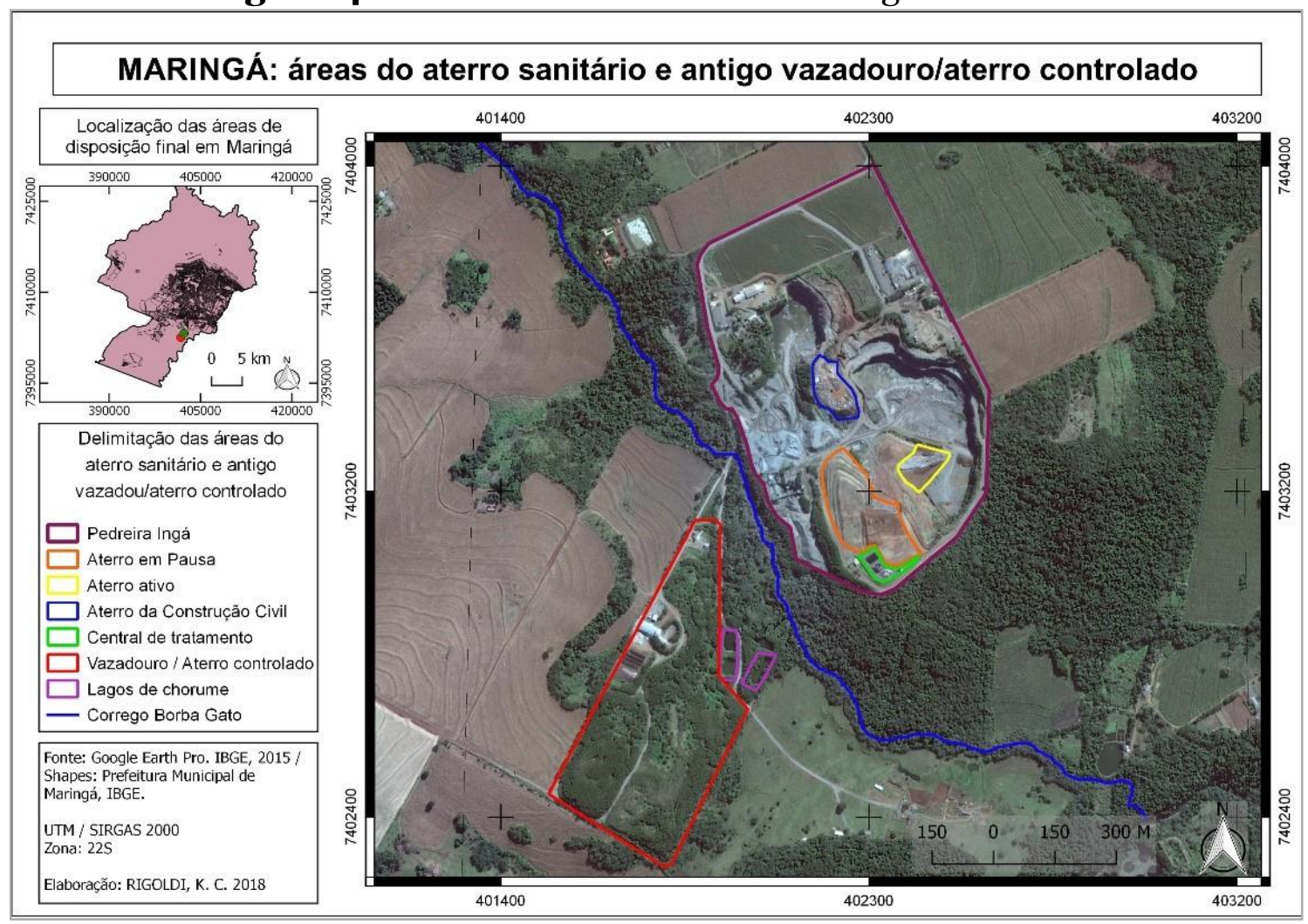

Elaborado por RIGOLDI, K.C.

O aterro possui capacidade total de, aproximadamente, 4 a 5 milhões de toneladas, e possuía, em 2017, uma expectativa de vida útil de, aproximadamente, 30 anos (informações fornecidas pelo engenheiro químico responsável pela área em 2017). Entretanto, no ano de 2018, o aterro começou a receber rejeitos/resíduos de outros municípios, a vida útil da área diminuiu para 19 anos.

Neste contexto, se a coleta seletiva for efetiva e atingir o estipulado no plano de gestão dos resíduos sólidos do município, o tempo de vida útil da área se estenderia a até 100 anos, caso esse aterro viesse a receber apenas resíduos do município de Maringá.

Em visitas técnicas realizadas em 2017, e no mês de maio de 2019, na área do antigo lixão da cidade, onde se localiza uma das cooperativas, a Coopervidros, verificou-se grande volume de materiais recicláveis 
acondicionados, irregularmente, na área do antigo lixão nas proximidades desta cooperativa (Figuras 5 e 6). Como observou-se em campo e em contato com a SEMUSP (2018), não há o controle da destinação dos caminhões para as cooperativas, nem a triagem dos materiais, fazendo com que algumas recebam pouco material para trabalhar, e nesta, há acúmulo e descarte irregular.

Figura 5: Materiais recicláveis dispostos de maneira irregular na Coopervidros, em Maringá (área do antigo lixão)

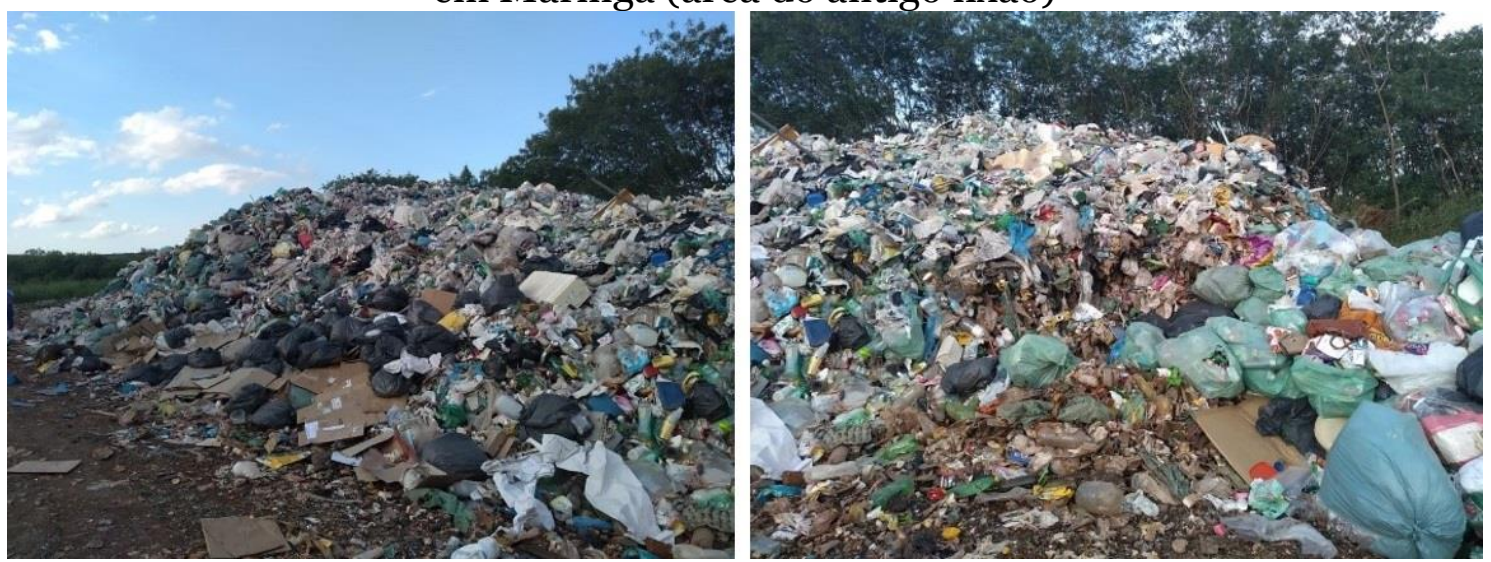

Fotografias: RIGOLDI, K.C..

Além destas questões apresentadas neste artigo, a cidade possui muitas áreas de disposição irregular, localizadas em terrenos vazios e nos fundos de vale. Foram identificados 31 pontos de descarte irregular de resíduos na área urbana da cidade (Figura 7). 
Figura 7: Áreas ilegais de descarte de resíduos sólidos em Maringá

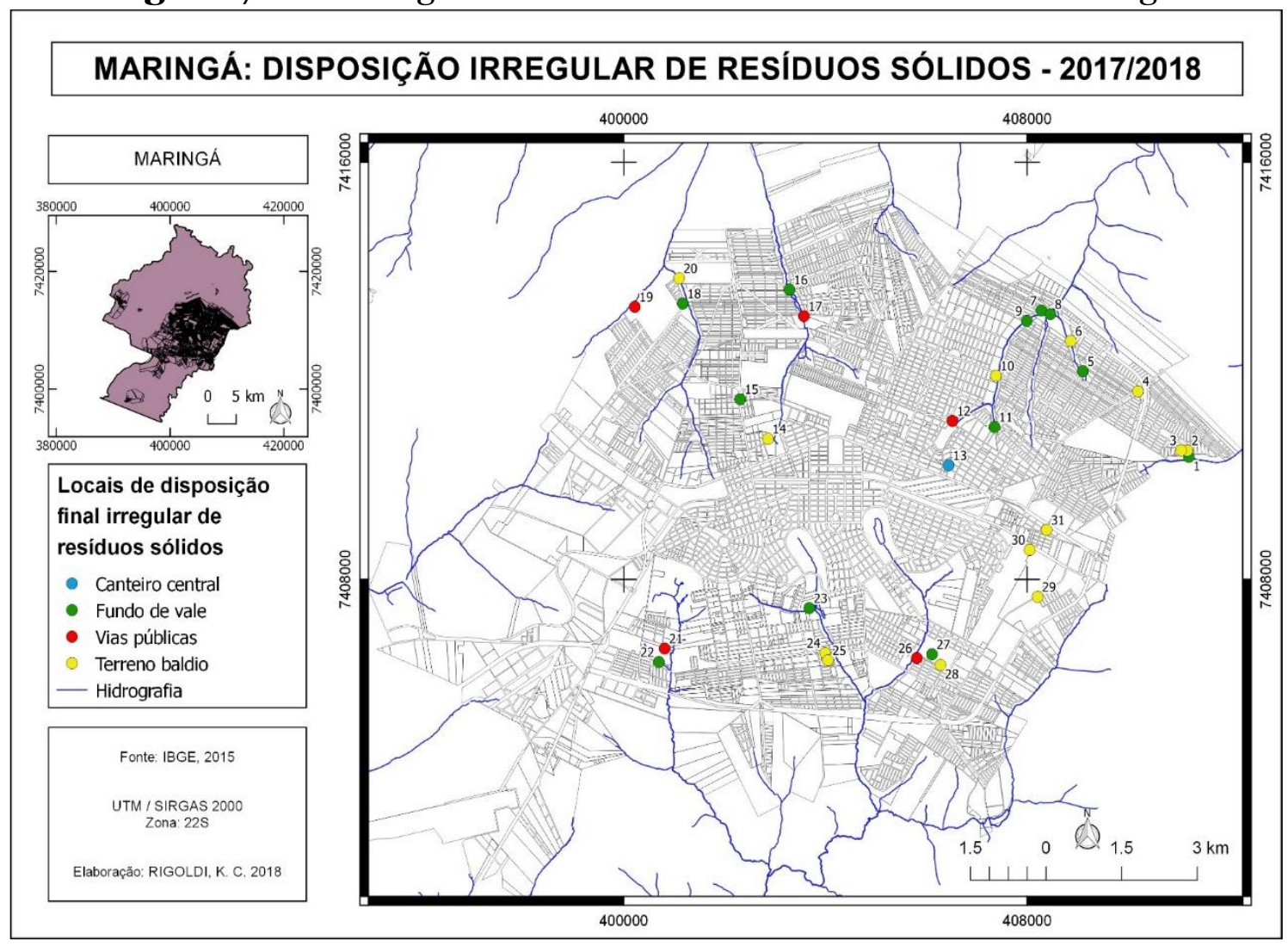

Fonte: Rigoldi e Lima (2019).

A maioria dos materiais observados foram: madeira, plástico, isopor, ferragens, eletrônicos, vidros e papelão, conforme Figuras 8 e 9.

Figura 8: Pontos de disposição irregular de resíduos na cidade de Maringá
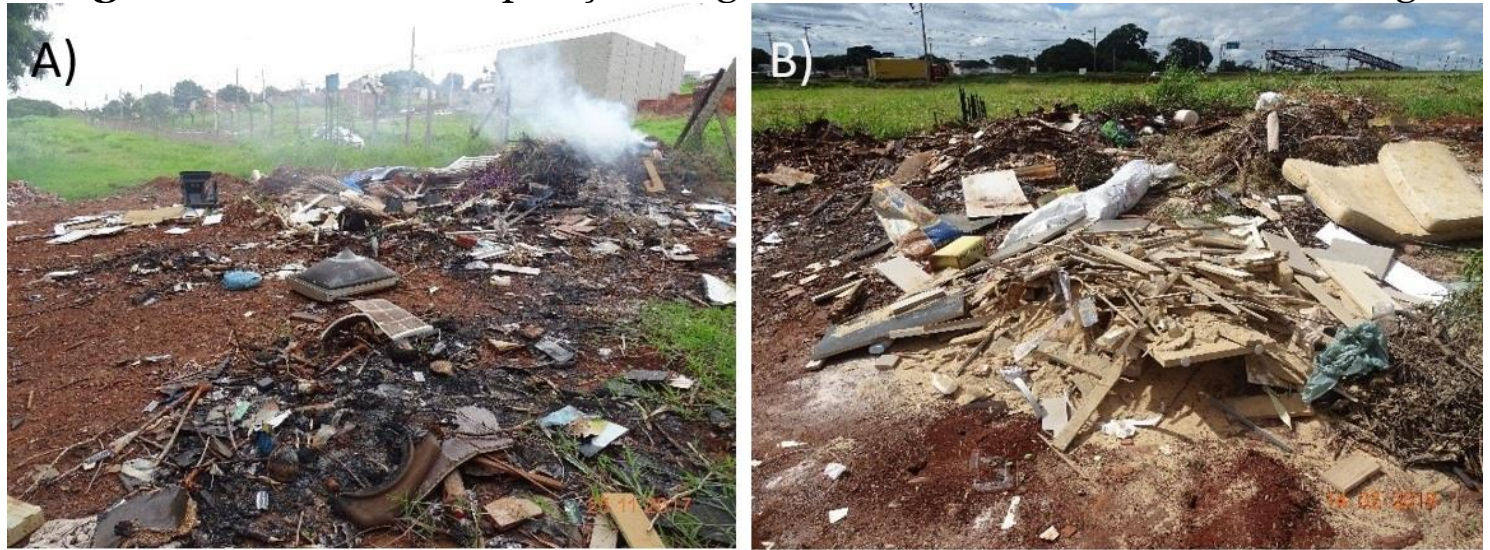

A) Ponto 1 da Figura 7; B) ponto 31 da Figura 7. Fotografias: RIGOLDI, K.C..

A partir dos dados disponibilizados pela SEMUSP (2018), pelas informações coletadas no PMGIRS da Prefeitura do Município de Maringá 
(2017) e, a partir de trabalhos de campo, verificamos que a coleta seletiva ainda é inexpressiva na cidade. Apenas $4 \%$ de todo o resíduo sólido coletado na cidade é encaminhado para a coleta seletiva, e segundo a prefeitura do município, aproximadamente $1 / 3$, ou seja, $33 \%$ de todo o resíduo coletado na cidade seria passível de reciclagem.

Mesmo após a implantação de um plano de gestão em 2017, a quantidade coletada não foi significativa, apenas em 2018 ocorreu pequeno aumento no contingente coletado. Desse modo, é notável a existência de falhas na gestão, principalmente, se forem verificadas a situação do acúmulo de materiais no antigo lixão da cidade e a ausência de controle efetivo no final do processo de coleta cujos caminhões são direcionados para as cooperativas.

\section{CONSIDERAÇÕES FINAIS}

Diante das análises realizadas, a questão dos resíduos sólidos na cidade é um dos problemas que impactam a qualidade ambiental. Apesar de apresentar tendência de diminuição da quantidade de resíduos recolhidos pela coleta convencional e o aumento dos recicláveis na coleta seletiva, esse se manifesta de maneira lenta, levando em considerando que a implantação do Plano de Gestão Integrada de Resíduos Sólidos Urbanos foi realizada em 2017 e, apenas no primeiro semestre de 2018, após novas modificações na atuação da coleta seletiva, que se obteve apenas $1 \%$ a mais de recicláveis recolhidos.

Neste sentido, conclui-se que é necessária a elaboração de ações que visem ao aperfeiçoamento do programa de coleta seletiva, como o mapeamento da rota dos caminhões, o controle dos materiais para as cooperativas, realização e ampliação da divulgação das mudanças que ocorrem no programa da coleta, assim como o calendário de coleta, dar continuidade às práticas positivas, como a distribuição dos sacos biodegradáveis. Além disso, destaca-se a importância de trabalhos de educação ambiental com a população a fim de sensibilizar a mesma para a separação correta e para a diminuição do consumo de produtos descartáveis. A partir destas ações, o programa de coleta seletiva poderia funcionar de maneira mais eficiente e, consequentemente, contribua para a melhoria da qualidade ambiental urbana. 


\section{REFERÊNCIAS}

ASSOCIAÇÃO BRASILEIRA DE NORMAS TÉCNICAS - ABNT. NBR 10.004. Resíduos sólidos: classificação. Rio de Janeiro: ABNT, 2004.

BRASIL. Lei no 12.305, de agosto de 2010. Institui a Política Nacional de Resíduos Sólidos; altera a Lei n ${ }^{\circ}$ 9.605, de 12 de fevereiro de 1998; e dá outras providências. Disponível em: http://www.planalto.gov.br/ccivil_03/_ato20072010/2010/lei/l12305.htm. Acesso em: 22 ago. 2019.

BRASIL. Lei no 12.690, de 19 de julho de 2012. Dispõe sobre a organização e o funcionamento das Cooperativas de Trabalho; institui o Programa Nacional de Fomento às Cooperativas de Trabalho - PRONACOOP; e revoga o parágrafo único do art. 442 da Consolidação das Leis do Trabalho - CLT, aprovada pelo Decreto-Lei ${ }^{\circ} 5.452$, de $1^{\circ}$ de maio de 1943. Disponível em: http://www.planalto.gov.br/ccivil_03/_Ato2011-2014/2012/Lei/L1269o.htm. Acesso em: 14 jun. 2019.

BRASIL. Ministério do Meio Ambiente. Plano Nacional de Resíduos Sólidos. Brasília: MMA, 2012.

BUSSAB, W. O.; MORETTIN, P. A. Estatística básica. 8. ed. São Paulo: Saraiva, 2013.

CALDERONI, S. Os bilhões perdidos no lixo. São Paulo: Humanitas, 2003.

CANCIAN, N. A. Cafeicultura paranaense (1900-1970). Curitiba: Grafipar - Secretaria de Estado da Cultura e do Esporte, 1981.

CANTÓIA, S. F. Coleta seletiva municipal, educação ambiental e organizações de catadores de materiais recicláveis na vertente paulista da bacia do Rio Paranapanema. 2012. Tese (Doutorado em PósGraduação em Geografia) - Universidade Estadual Paulista, Presidente Prudente, 2012.

COSTA, J. N. M. N.; DURGAN, G. Leucaena leucocephala (Lam.) de Wit (Fabaceae): Invasora ou Ruderal? Revista Árvore, Viçosa, v. 34, n. 5, p. 825833, 2010.

DAS, K. R.; IMON, A. H. M. R. A Brief Review of Tests for Normality. American Journal of Theoretical and Applied Statistics, v. 5, n. 1, p. 5$12,2016$.

DIRETORIA DE COMUNICAÇÃO PMM. Serviços Públicos organiza coleta seletiva no município. Prefeitura de Maringá [online], 13 fev. 2017. Disponível em: http://www2.maringa.pr.gov.br/site/index.php?sessao=6fa2d61 15e556f\&id=30240. Acesso em: 9 fev. 2018.

GUJARATI, D. N.; PORTER, D. C. Econometria básica. 5. ed. Porto Alegre: AMGH, 2011. 
HOGAN, D. J. A Qualidade Ambiental urbana: oportunidades para um novo salto. São Paulo em perspectiva, São Paulo, v. 9, n. 3, p. 17-23, 1995.

INSTITUTO BRASILEIRO DE GEOGRAFIA E ESTATÍSTICA - IBGE. Estimativas da População Residente nos Municípios Brasileiros com Data de Referência em $1^{\circ}$ de julho de 2018. IBGE, 2018

INSTITUTO DE PESQUISAS TECNOLOGICAS - IPT. Lixo municipal: manual de gerenciamento integrado. São Paulo: CEMPRE, 2018.

MARQUES, J. R. Meio ambiente urbano. 1. ed. Rio de Janeiro: Forense Universitária, 2005.

MENDONÇA, F. Riscos, vulnerabilidade e abordagem socioambiental urbana: uma reflexão a partir da RMC e de Curitiba. Desenvolvimento e Meio Ambiente, Curitiba, n. 10, p. 139-148, jul./dez. 2004.

MONTEIRO, J. H. P. et al. Manual do gerenciamento integrado de resíduos sólidos. Rio de Janeiro: IBAM, 2001.

MORAES, E. Diagnóstico da Gestão de Resíduos Sólidos Urbanos de sete municípios da região metropolitana de Maringá, Paraná. 2011. Dissertação (Mestrado em Engenharia Urbana) Universidade Estadual de Maringá, Maringá, 2011.

PEIXOTO, K.; CAMPOS, V. B. G; D’AGOSTO, M. A. A coleta seletiva e a redução de resíduos sólidos. Rio de Janeiro: Instituto Militar de Engenharia, 2005. Disponível em: http://aquarius.ime.eb.br/ webde2/prof/va nia/pubs/(7)coletaresiduossolidos.pdf-. Acesso em: 20 mar. 2019.

PESSOA, D. de S. et al. Avaliação de impactos ambientais em área de disposição final de resíduos sólidos no semiárido. GeoGraphos, v. 10, n. 121, p. 269-294, 2019. Disponível em: https://web.ua.es/revista-geographosgiecryal. Acesso em: 15 abr. 2020.

PREFEITURA DO MUNICÍPIO DE MARINGÁ - PMM. Contrato 323/2017. Contratação de empresa especializada para execução de serviços de destinação final dos resíduos sólidos urbanos com característica de domiciliares gerados no município de Maringá/PR, em aterro sanitário devidamente licenciado conforme as determinações da legislação vigente, pelo período de 12 (doze) meses, por solicitação da Secretaria Municipal de Serviços Públicos, através da Secretaria de Patrimônio, Compras e Logística - SEPAT. Disponível em: http://venus.maringa.pr.gov.br:8090/portaltransparencia/contratos/detalhes? entidade $=1 \&$ exercicio $=2017 \&$ contrato=1403. Acesso em: 13 mar. 2018 .

PREFEITURA DO MUNICÍPIO DE MARINGÁ - PMM. Plano Municipal de Gestão de Resíduos Sólidos Urbanos - Anexo I. Maringá: PMM, 2017. Disponível em: http://www.cmm.pr.gov.br/residuosSolidos/plano.pdf. Acesso em: 30 nov. 2017. 
PREFEITURA DO MUNICÍPIO DE MARINGÁ - PMM. Coleta Seletiva em Maringá. Prefeitura de Maringá [online], [s. d.]. Disponível em: http://www .maringa.pr.gov.br/htmls/coleta_seletiva.htm. Acesso em: 15 fev. 2018.

QGIS. QGIS Geographic Information System. Open Source Geospatial Foundation Project. QGIS [online], [s. d.]. Disponível em: http://qgis.osgeo.org. Acesso em: 16 set. 2019.

RAMOS, S. P.; SANTOS, S. L. S.; OLIVEIRA, F. A. de. Lei da política nacional de resíduos sólidos: análise conceitual de destinação e disposição adequadas de resíduos sólidos. Revista Interdisciplinar Científica Aplicada, Blumenau, v. 14 , n. 1, p. 1-14. 2020.

RIGOLDI, K. C.; LIMA, V. A gestão dos resíduos sólidos e sua influência na qualidade ambiental de Maringá-PR. In: CONGRESSO INTERNACIONAL DE POLÍTICA SOCIAL E SERVIÇO SOCIAL: DESAFIOS OCNTEMPORÂNEOS. SEMINÁRIO NACIONAL DE TERRITÓRIO E GESTÃO DE POLÍTICAS SOCIAIS. CONGRESSO DE DIREITO À CIDADE E JUSTIÇA AMBIENTAL. 3., 4., 3., 2019, Londrina. Anais [...]. Londrina: UEL, 2019. Disponível em: https://www.congressoservicosocialuel.com.br/trabalhos2019/assets/4604232609-36435-2019-04-09.pdf. Acesso em: 4 set. 2019.

RIGOLDI, K. C.; LIMA, V. Qualidade Ambiental e Resíduos Sólidos Urbanos: uma análise do programa de coleta seletiva da cidade de Maringá. In:

SIMPÓSIO INTERNACIONAL DE QUALIDADE AMBIENTAL. 11., 2018, Porto Alegre, 2018. Anais [...]. Porto Alegre: PUCRS, 2018. Disponível em:

http://www.abes-

rs.uni5.net/centraldeeventos/_arqTrabalhos/trab_2_5545_20180820132728.p df. Acesso em: 10 ago. 2019.

RODRIGUES, A. M. Produção e consumo do e no espaço: Problemática ambiental urbana. São Paulo: Hucitec, 1998.

SANTOS, M. A natureza do espaço: técnica e tempo. Razão e emoção. 4. ed. São Paulo: Editora da Universidade de São Paulo, 2006.

SANTOS, M. A questão do meio ambiente: desafios para a construção de uma perspectiva transdisciplinar. Geotextos, v. 1, n. 1, p. 139-151, 2005. Disponível em: https://portalseer.ufba.br/index.php/geotextos/article/view/3033/2142. Acesso em: 15 jun. 2019.

SANTOS, J. E. dos; SANTOS V. L. da C. O período técnico-científicoinformacional e o ensino de geografia: algumas notas. Caminhos da Geografia, Uberlândia, v. 12, n. 18, p. 168-18o, 2011.

SECRETARIA DE SERVIÇOS PÚBLICOS - SEMUSP. Protocolo 45988/2018. Maringá: SEMUSP, 2018. 
Recebido em 11 de outubro de 2019 Aceito em 21 de maio de 2020 